\title{
Decenoic Acid
}

National Cancer Institute

\section{Source}

National Cancer Institute. Decenoic Acid. NCI Thesaurus. Code C68338.

A monounsaturated medium-chain fatty acid with a 10-carbon backbone. Decenoic acid is found rarely in nature. 